\title{
Unusual false passage formation during nasogastric tube insertion in an anesthetized patient
}

\author{
Upasana Goswami and Savita Babbar \\ Department of Anesthesiology, Deen Dayal Upadhyay Hospital, New Delhi, India
}

A 54-year-old male patient of physical status I, according to the American Society of Anesthesiologists, and weighing 60 $\mathrm{kg}$, with a history of enteric perforation and laparotomy done 3 months back, was scheduled to undergo ileostomy closure. A nasogastric tube (NGT) was required both intra- and post-operatively as there would be bowel handling. Following induction of anesthesia, an attempt was made to insert the NGT through the right nostril, which failed due to resistance. After this initial attempt, two more gentle attempts were made through the left nostril without any success. In both instances, resistance was met at approximately $15 \mathrm{~cm}$ from the nostrils. Upon direct laryngoscopy by a senior anesthesiologist, the NGT was discovered to be in the submucosal track in the posterior pharyngeal wall. A pediatric fiberoptic bronchoscope (FOB) with an outer diameter of $3.4 \mathrm{~mm}$ was therefore inserted through the right nostril, which revealed a tear in the nasopharynx. A false submucosal passage formed beyond the tear, which ended in the oropharynx. Even under FOB vision, the NGT continued to migrate into the false passage upon subsequent maneuvers. Therefore, a no. 1 silk was tied to the FOB tip and pulled out from the oral cavity. The nasal end of the silk was then detached from the FOB and tied to the NGT, which was pulled in through the left nostril, while the FOB was inserted through the right nostril, and held in po- sition in the nasopharynx. The NGT was then inserted into the esophagus under vision (laryngoscopy) with the help of Magill's forceps. Although a literature search suggested that NGT may cause various minor and major traumas $[1,2]$, the standard practice involves insertion of this simple, yet potentially hazardous device blindly into anesthetized patients in the operating room. Though the insertion of NGT is routinely performed under vision only in select patients, for e.g., those with basal skull fractures [3], it is preferable to follow the same procedure for all patients. The videolaryngoscope is being used more frequently for insertion of the NGT under vision, with greater success and fewer complications [4]. However, the trauma caused in this case was unique, as it occurred in a healthy patient with no history of trauma and minimal manipulation for the insertion of the NGT. The trauma in the nasopharynx was managed conservatively with antibiotics and xylometazoline drops for 7 days to prevent wound infection, as advised by the otorhinolaryngologist, and satisfactory healing was achieved. Even if the NGT was inserted under vision with any laryngoscope, this trauma or complication was probably inevitable, as the site of trauma was in the nasopharynx. An endoscope-guided insertion of the NGT [5] through the nose may be helpful in such a situation.

\footnotetext{
Corresponding author: Upasana Goswami, M.D.

Department of Anesthesiology, Deen Dayal Upadhyay Hospital, New Ashiana Apt, plot 10 sector 6, Dwarka, New Delhi 110075, India Tel: 919718990118, Fax: 919718990118, Email: upagoswami@gmail.com

ORCID: https://orcid.org/0000-0002-9596-5846
}

Received: February 19, 2018. Revised: March 22, 2018. Accepted: March 25, 2018.

Korean J Anesthesiol 2018 October 71(5): 415-416

https://doi.org/10.4097/kja.d.18.00045

(c) This is an open-access article distributed under the terms of the Creative Commons Attribution Non-Commercial License (http://creativecommons.org/ licenses/by-nc/4.0/), which permits unrestricted non-commercial use, distribution, and reproduction in any medium, provided the original work is properly cited. 


\section{References}

1. Michel I, Veyckemans F, Van Boven M. Unusual complication of a nasogastric tube insertion. Anesth Analg 1997; 84: 471.

2. Wu PY, Kang TJ, Hui CK, Hung MH, Sun WZ, Chan WH. Fatal massive hemorrhage caused by nasogastric tube misplacement in a patient with mediastinitis. J Formos Med Assoc 2006; 105: 80-5.

3. Lee BB. Nasotracheal intubation in a patient with maxillo-facial and basal skull fractures. Anaesthesia 2004; 59: 299-300.

4. Moharari RS, Fallah AH, Khajavi MR, Khashayar P, Lakeh MM, Najafi A. The GlideScope facilitates nasogastric tube insertion: a randomized clinical trial. Anesth Analg 2010; 110: 115-8.

5. Kelly G, Lee P. Nasendoscopically-assisted placement of a nasogastric feeding tube. J Laryngol Otol 1999; 113: 839-40. 